This is the final peer-reviewed accepted manuscript of:

Cassani, E., Barichella, M., Ferri, V., Pinelli, G., lorio, L., Bolliri, C., Caronni, S., Faierman, S.A., Mottolese, A., Pusani, C., Monajemi, F., Pasqua, M., Lubisco, A., Cereda, E., Frazzitta, G., Petroni, M.L., Pezzoli, G., 2017. Dietary habits in Parkinson's disease: Adherence to Mediterranean diet. Parkinsonism Relat. Disord. 42, 40-46. https://doi.org/10.1016/j.parkreldis.2017.06.007

The final published version is available online at: https://doi.org/10.1016/i.parkreldis.2017.06.007

Rights / License:

The terms and conditions for the reuse of this version of the manuscript are specified in the publishing policy. For all terms of use and more information see the publisher's website.

This item was downloaded from IRIS Università di Bologna (https://cris.unibo.it/)

When citing, please refer to the published version. 


\section{Dietary habits in Parkinson's disease: Adherence to Mediterranean diet}

Erica Cassani a, *, Michela Barichella a, Valentina Ferri a, Giovanna Pinelli a, b, Laura Iorio a,Carlotta Bolliri a, Serena Caronni a,

Samanta A. Faierman a, Antonia Mottolese a,

Chiara Pusani a, Fatemeh Monajemi a, Marianna Pasqua a, Alessandro Lubisco c,

Emanuele Cereda d, Giuseppe Frazzitta e, Maria L. Petroni f, Gianni Pezzoli a

a Parkinson Institute, ASST G.Pini-CTO, ex ICP, Milan, Italy

b Department of Parkinson Disease Rehabilitation, Moriggia-Pelascini Hospital, Gravedona ed Uniti, Fondazione Europea Ricerca Biomedica (FERB), Italy

c Department of Statistical Sciences "P. Fortunati", University of Bologna, Bologna, Italy

d Nutrition and Dietetics Service, Fondazione IRCCS Policlinico San Matteo, Pavia, Italy

e Department of Parkinson's disease and Brain Injury rehabilitation, Moriggia-Pelascini Hospital, Gravedona ed Uniti, Como, Italy

f Scientific Coordinator of Osservatorio Grana Padano, Italy

* Corresponding author.

E-mail address: erica.cassani@live.it (E. Cassani).

\section{Abstract}

Introduction: Our objective is to describe the dietary habits, food preferences and adherence to Mediterranean diet (MeDi) of a large sample of Italian Parkinson's Disease (PD) patients compared to a group of controls.

Methods: Dietary habits of 600 PD patients from throughout Italy and 600 controls matched by gender, age, education, physical activity level and geographical residence, were collected using the ON-GP Food Frequency Questionnaire. Then, we compared patients by disease duration and the presence of swallowing disturbances.

Results: Overall, adherence of PD patients (males, 53.8\%; mean disease duration, $9.2 \pm 7.0$ years) to MeDi was similar to controls (score, $4.8 \pm$ 1.7 vs. $4.9 \pm 1.6$; $\mathrm{P} 1 / 4$ 0.294). Patients consumed less alcohol and fish and drank significantly less water, coffee, and milk which resulted also in lower total fluids intake. On the contrary, they ate more fruit, cooked vegetables, cereals and baked items, more dressings and more sweets in general. Disease duration was associated with increased intake of several food groups but it was not associated with changes in MeDi

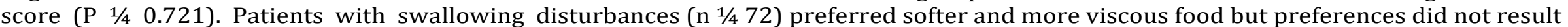
in differences in dietary pattern. However, patients with dysphagia drank less fluids $(\mathrm{P}=0.043)$.

Discussion: PD patients presented different dietary habits and food preferences compared to the general population and adherence to MeDi was not associated with disease duration. Self-reported dysphagia was associated with reduced intake of fluids. These aspects may be amenable to change in order to improve the management of nutritional issues in this patient population. 


\section{Introduction}

Besides having a potential role in the etiopathogenesis of the disease [1,2], nutrition has an important role to play in the integrated management of Parkinson's disease (PD) [3]. Body weight can variably modify during the course of the disease. Weight loss may characterize the pre-clinical stage of the disease, while weightgain in the first years of the disease may reflect benefits deriving from positive response to pharmacological treatments. Disease progression is associated with body weight reduction despite compensatory food intake, even in presence of increasing food intake, whilst neurosurgical procedures usually result in importantweight gain and related metabolic complications [3,4]. Dietary amino acids (especially neutral amino acids) compete with levodopa for absorption from the gut and through the blood-brain barrier, reducing the efficacy of the drug [5]. To optimize the effects of levodopa, PD patients should follow a protein redistribution diet, with a low-protein lunch and protein intake in the evening. Some patients may require cereal devoid of protein for lunch [6].

Dysautonomic manifestations could get significant benefit from dietary management $[3,7]$. Approximately, $60 \%$ of patients suffer from constipation. This makes a fiber-rich diet together with correct hydration essential [8]. Besides, probiotics and prebiotics may be a useful adjuvant therapy [9]. Dysphagia for solid food or liquids or both occurs in the advanced stages and is associated with the risk of complications, which may even be serious, such as malnutrition or ab ingestis pneumonia [10]. A semisolid diet and the use of thickeners are required to treat dysphagia, while in some cases enteral nutrition is required.

These considerations show how important nutrition is in PD and how investigations on dietary habits of PD patients can provide findings of considerable interest. To date, few investigations have been performed in PD patients and their sample size was small [11-14]. In a recent article [4] we described micronutrients and macronutrients intake in a large group of PD patients and focused on energy balance, protein redistribution, the influence of protein intake on levodopa therapy, and constipation. However, in the last two decades, there has been also growing interest in the possible implications of dietary pattern, particularly the Mediterranean diet (MeDi). A prospective study has shown an inverse association be- tween adherence to MeDi and risk of PD [2]. A recent case-control study conducted in the US has found that PD patients adhere less than controls to a Mediterranean-type diet and their behavior was associated with age at onset [11]. To expand the knowledge in this area, the objective of this study was to assess dietary habits, food preferences and adherence to MeDi in Italian PD patients compared to controls and in-between patients with and without self-perceived swallowing difficulties.

\section{Methods}




\subsection{Study population}

We conducted a large case-control observational study [4]. Dietary habits and lifestyle of patients suffering from idiopathic Parkinson's disease (PD) with normal cognitive functions (MMSE >24 points), from all Regions of Italy and recruited consecutively among the PD patients attending the outpatient neurology clinic of the Parkinson Institute (ASST G. Pini-CTO, ex ICP, Milan, Italy) were the subject of this study. The Parkinson Institute is located in Lombardy, the most populated Region of Italy (total inhabitants: 10.003.419-

www.demo.istat.it [accessed 18th January 2016]). The dietary habits of the patients were then compared with those of a control group matched [1:1] by gender, age [ \pm 1 year], education, physical activity level and geographical area. Controls were selected among all the patients in the database of the "ON-GP" software freeware online, developed by the Grana Padano Observatory (OGP) [15,16]. Some of the controls were the spouses of the patients included or people accompanying them or other patients attending the hospital for other minor health reasons (minor neurologic, orthopedic, dermatologic [not allergic] or ophthalmologic disorders). Subjects and patients reporting the use of any type of dietary supplement and/or receiving artificial nutritional support were excluded. All the subjects recruited provided their informed consent to the study. The study was approved by the local Ethics Committee.

\subsection{Assessments}

The online "ON-GP" Software freeware was used [15,16]. This software is able to collect the following information: gender; age; geographical area (residence); education; type of occupation; anthropometric data (body weight, height, body mass index [BMI]); time dedicated to household chores, free time dedicated to sedentary hobbies and physical activity. Based on this information, the software then provides an estimate of resting energy expenditure (REE) according to the Harris-Benedict equations [17] and physical activity level (PAL) according to Italian guidelines (LARN) [18].

Trained dieticians (not blinded to diagnosis) completed the questionnaire by interviewing patients directly (with the aid of caregivers whenever necessary to avoid missing items). 24-hour dietary recall associated with the use of a food atlas was also considered for consistency of portion size. Dietary habits were investigated with a semi-quantitative 66-item Food Frequency Questionnaire (FFQ) included in the "ON-GP" Software $[15,16]$, with the objective of assessing the frequency of consumption of the main food groups and drinks over the last 12 months. Moreover, the software provided the calculation of daily calorie, macronutrient, micronutrient and fluid intakes according to the Italian Food Composition Tables [19]. In this way any excesses and/or deficiencies were highlighted. Based on the data processed, the soft- ware enabled us to print a report containing personalized advice to give the patient.

All the histories were then saved and collected in a password-

protected, web-based database, which can be extracted in Excel format and used for statistical analyses. Then, for each participant we calculate the MeDi score (range: 0 to 9 points; higher score indicated greater adherence to the MeDi) according to the well- established method recently used also by Alcalay et al. [11,20] for conducting a similar analysis in PD patients. First, we regressed caloric intake (measured in kilocalories) and calculated the derived residuals of daily gram intake for each of the following 7 food categories: dairy, meat, fruits, vegetables, legumes, cereals, and fish. Therefore, 1 point was assigned for each beneficial component (fruits, vegetables, 
legumes, cereals, and fish) whose caloric- adjusted intake was equal or above the sex-specific median. Then, detrimental components (meat and dairy products) whose caloric- adjusted intake equal or below the median were scored similarly. Intake ratio of

monounsaturated fats to saturated fats above the sex-specific median and mild to moderate alcohol consumption ( $>0$ to $<30 \mathrm{~g} / \mathrm{day})$ were also given 1 point each. Participants were given a zero for each of the categories if the caloric-adjusted consumption was outside the range described above.

Furthermore, on the same day and in collaboration with the neurologist, the following clinical information was collected for all PD patients by interviewing: duration of disease, Unified Parkinson Disease Rating Scale (UPDRS) from part I to part IV [21], and disease severity (Hoehn and Yahr [HY] staging system) [22]. The presence of swallowing disturbances was assessed using the specific item of UPDRS part II which is consistent with the screening question included in the "Non Motor Symptom Questionnaire" ("Have you experienced any difficulty in swallowing food or drink or problem with choking?") recommended by the task force of the Movement Disorders Society $[23,24]$.

\subsection{Statistical analysis}

All analyses were performed using the SPSS 23.0 for Windows (SPSS Inc., Chicago, Illinois). All statistical tests were two-tailed, and a pvalue $<0.05$ was assumed to be statistically significant. Descriptive statistics of categorical variables were presented as counts and percentages, while continuous variables were reported as mean and standard deviation. Particularly, data on foods consumption were presented as crude values (unadjusted for energy intake) as they were not collected to address the pathophysiologic role of diet in PD.

Between-group comparisons of continuous variables were per-formed using the Student's t-test (between two groups) and ANOVA (among multiple groups). Particularly, a t-test for paired data was used to compare patients and controls, while in the other cases an unpaired t-test was adopted. Categorical variables were analyzed by Fisher's exact test. First, data on principal food consumptions were compared between PD patients and controls. Then, the dietary habits of patients were compared across tertiles of disease duration, and by presence of swallowing disturbances.

\section{Results}

A total of 600 PD patients (males, 53.8\%; mean age, 68.6 \pm 9.4 years; mean disease duration, $9.2 \pm 7.0$ years) and 600 controls (mean age, $68.6 \pm 9.4$ years) from all over Italy were interviewed. The comparison of the mean values of the two groups disclosed that PD patients had lower BMI $(26.2 \pm 4.9$ vs. $28.5 \pm 6.4 \mathrm{~kg} / \mathrm{m} 2 ; \mathrm{P}<0.001)$, although their intake of calories, macronutrients and different micronutrients (iron, zinc, vitamin A, C and folates) was significantly higher [4].

Mean daily intake (in g or $\mathrm{ml}$ ) of foods and drinks was estimated. The results are shown in Table 1. It can be seen that PD patients drank significantly less water, coffee, tea, milk (either skimmed or partly skimmed or whole), alcoholics - which resulted also in lower total fluids intake (1594 \pm 546 vs. $1884 \pm 560 \mathrm{~mL} /$ day; $\mathrm{P}<0.001)$ - and consumed less fish. Their consumption of meat and cured meat was 
lower, albeit not significantly. They ate more soy milk or yogurt, fruit, cooked vegetables, cereal and baked items, more dressings and more sweets in general. They usually ate softer and more viscous food, which is more suitable for people who have difficulty swallowing, such as vegetable pure'e, milk puddings and custards, ice cream and oil. Despite the higher intake of several food groups in PD patients than controls, no significant differences were observed in dietary pattern (P 0.294; Fig. 1).

Then, given the positive association previously found between disease duration and protein-calorie intake [4], we evaluated its relationship also with dietary habits. Disease duration was associ- ated with increasing intake of different food groups, such as soft dairy products, soy milk or yogurt, pasta and rice, vegetable soup/ pure'e, margarine, and milk puddings and custards. Oatmeal consumption appeared to increase at the expenses of sweetened breakfast cereals. The same applied to sweets containing sugar, milk puddings and custards in replace of other sweet snacks, while longer duration was associated with reduced consumption of arti- ficial sweeteners, seed oil and coffee (Supplementary Table 1). However, we did not observe significant changes in dietary pattern with disease duration (for trend over tertiles of MeDi score, P 0.721), even after adjusting for potential confounders (gender, age at onset, physical activity level and education; P 0.622) (Fig. 1). No association was also found between MeDi score and ageat onset.

Swallowing disorders were reported by 72 patients $(12 \%)$ and were positively associated with male gender, disease severity, and age at assessment but did not resulted in differences in body weight, BMI, and calorie and nutrient intake (Table 2). Patients with dysphagia drank less water ( $P$ 0.011), milk and fluids in general ( $\mathrm{P}$ 0.043) but consumed more fizzy drinks. They preferred softer and more viscous foods (Table 3), such as yogurt, pasta and po- tatoes (instead of bread and pizza), cooked and pureed vegetables (instead of raw ones), milk puddings and custards (instead of other sweet snacks and chocolate) and consumed more oil (instead of other dressings). Sweetened breakfast cereals and legumes were preferred to oatmeal and eggs, respectively. However, no effect on MeDi score was detected $(\mathrm{P}=0.638)$.

\section{Discussion}

In the present study we observed that PD patients have different dietary habits and food preferences than controls but these differences did not appear to influence adherence to MeDi. Disease duration was associated with changes in the consumption of some food groups but again these did not influence dietary pattern. Finally, swallowing disturbances did not appear to be associated with MeDi score although patients reporting them preferred softer and more viscous foods.

Regarding dietary habits, the significant reduction in fish consumption, and the trend to reduced intake of meat and cured meat may be due to an erroneous interpretation of the protein redistribution diet. Patients did not curb the consumption of other sources of protein, such as eggs and dairy products (cheeses, sweetened yogurt) and actually consumed more of them than controls. The reduction in milk consumption may be the result of the decision to have a low protein breakfast [5,6], and to make up for this PD patients eat a sweetened yogurt as a snack in the afternoon or after dinner. Also the increased consumption of soy milk may be due to an erroneous interpretation of the protein redistribution diet, since some patients consider it a low protein choice, to be used also at breakfast. The reduced consumption of coffee and alcohol is consistent with the well-known behavioral traits of PD patients before the onset of the disease i.e. their ten- dency to avoid any kind of vice. Furthermore, coffee and also tea may be reduced to avoid worsening of tremor [25], whereas 
alcohol intake may be diminished because of the fear of interactions with pharmacological therapy. The increased intake of sweets (which was significant for milk puddings and custards) may be an attempt to compensate for depression, which is common in PD [13] but the seeking for more tasty foods could be influenced also by hyposmia [6,26].

Nowadays, there is also growing interest in the health implications of dietary pattern and adherence to MeDi. Higher adherence to this has been associated with lower risk of neurodegenerative diseases [27], including PD, but also with longer survival in Alz- heimer's disease [28]. Concerning to Mediterranean Diet, PD patients tend to consume less fish and legumes but ate more eggs than controls, while the intake of dairy products was almost similar. However, they consumed less alcohol and more oil. Refined cereals and potatoes were preferred to products made with whole flour and patients consumed less fresh fruit and raw vegetables but ate more cooked and pureed vegetables. These are reasonable interchanges to cope with the need of a good fiber intake due to constipation. Our results are different from those provided by Alcalay et al. [11], who reported a lower adherence of PD patients to MeDi. This discrepancy could be explained by differences in food preferences associated with ethnicity and the fact that the present study has been conducted at a movement disorders clinic, in which nutritional care is integrated with neurologic clinical activities [4]. Besides, we report that, although mean MeDi score values in this study may appear lower than expected, adherence to MeDi is similar to that of other Italian studies conducted in middleaged and old adults $[29,30]$.

The above indicated food preferences of PD patients may be also justified by the presence of chewing and swallowing difficulties in PD patients. Consistently with our previous report [23], 12\% of patients were suffering from swallowing disturbances. Indeed, their presence could explain the increased consumption of soft and viscous food, such as potatoes, vegetable puree, cooked vegetables, milk puddings and custards, and olive oil. Texture-modified diets are the first-line strategy in the management of dysphagia [31]. It is interesting to note that body weight, BMI or calorie or nutrient intake were comparable in patients with and without self-reported dysphagia. Swallowing impairment, despite being a life- threatening condition responsible for aspiration pneumonia [10], likely results in malnutrition only when severity is such to require artificial nutrition. Besides, nutritional care is provided on a routine basis at our institute [4]. However, in the initial stages neurogenic dysphagia likely affects fluids intake [10]. This is consistent with our findings, even if patients with swallowing disturbances consumed more fizzy drinks, which are likely to results in more efficacious swallowing [32]. At the base New Italian Eating Pyramid [33] there are hydration and regular physical activity. In subjects

over 65 years, the recommended daily hydration is at least of $2 \mathrm{~L}$ of water/day. Our PD patients drink only about $1 \mathrm{~L}$ of water $(50 \%$ of the recommended) and also total fluid intake (despite not taking into account the water from foods) was below the recommended threshold. Therefore, fluid intake should be consider a major nutritional issue in this patient population and we cannot exclude that recommending the use of liquid thickeners e as appropriate e may help improving it. Nonetheless, despite the absence of specific tools for assessing swallowing disturbances in PD, we recognize as a limitation of our study the use of the specific item of UPDRS part II. Although it is consistent with the screening question included in the "Non Motor Symptom Questionnaire" ("Have you experienced any difficulty in swallowing food or drink or problem with choking?") recommended by the task force of the Movement Dis- orders Society [24], previous studies have shown that up to $80 \%$ of PD patients present an impairment in swallowing when they are assessed using objective methods [34].

Another limitation we acknowledge is the shortness of the list of foods investigated (compared to other available tools), which could 
result not only in under- and over-reporting but also, for example, in difficulties in assessing seasonal variation on dietary reporting. Nonetheless, although food frequency questionnaires are appropriate for epidemiologic research, some other tools are needed to better assess nutritional status and dietary intakes in clinical care. Finally, we cannot exclude some bias associated with the study site where nutritional care is integrated with neurologic clinical activities.

Thanks to the study of dietary habits in such a large sample of patients, we have shown the importance of focusing also on dietary habits and food preferences in PD patients.

Particularly, the study enabled to identify additional key nutritional aspects that experts in PD can address by correcting dietary mistakes of the patients. Furthermore, our work paves the way for a future study with a prospective longitudinal design, which would enable us to relate the most characteristic nutritional habits of newly diagnosed PD patients to the etiopathogenesis of the disease and to its progression. With this perspective, the use of validated tools for the assessment of dietary habits is recommended.

\section{Acknowledgments}

We wish to thank: the "Fondazione Grigioni per il morbo di Parkinson" and "Brain and Malnutrition in Chronic Diseases Asso- ciation" for financial support; Jennifer S Hartwig, MD for assistance in editing the manuscript; Dr. Pier Danio Forni (OSC Healthcare S.r.l Unipersonale) and Consorzio Grana Padano for software use and management.

\section{References}

[1] Z.S. Agim, J.R. Cannon, Dietary factors in the etiology of Parkinson's disease, Biomed. Res. Int. 2015 (2015) 672838.

[2] X. Gao, H. Chen, T.T. Fung, G. Logroscino, M.A. Schwarzschild, F.B. Hu,

A. Ascherio, Prospective study of dietary pattern and risk of Parkinson disease, Am. J. Clin. Nutr. 86 (5) (2007 Nov) $1486-1494$.

[3] M. Barichella, E. Cereda, G. Pezzoli, Major nutritional issues in the manage- ment of Parkinson's disease, Mov. Disord. 24 (13) (2009 Oct 15) 1881-1892.

[4] M. Barichella, E. Cereda, E. Cassani, G. Pinelli, L. Iorio, V. Ferri, G. Privitera,

M. Pasqua, A. Valentino, F. Monajemi, S. Caronni, C. Lignola, C. Pusani, C. Bolliri,

S.A. Faierman, A. Lubisco, G. Frazzitta, M.L. Petroni, G. Pezzoli, Dietary habits and neurological features of Parkinson's disease patients: implications for practice, Clin. Nutr. 36 (4) (2017), 1054-1061.

[5] E. Cereda, M. Barichella, C. Pedrolli, G. Pezzoli, Low-protein and protein- redistribution diets for Parkinson's disease patients with motor fluctuations: a systematic review, Mov. Disord. 25 (13) (2010 Oct 15) 2021-2034.

[6] E. Cereda, M. Barichella, G. Pezzoli, Controlled-protein dietary regimens for Parkinson's disease, Nutr. Neurosci. 13 (1) (2010 Feb) $29 \mathrm{e} 32$.

[7] A. Fasano, N.P. Visanji, L.W. Liu, A.E. Lang, R.F. Pfeiffer, Gastrointestinal dysfunction in Parkinson's disease, Lancet Neurol. 14 (6) 
(2015 Jun) 625-639.

[8] M. Rossi, M. Merello, S. Perez-Lloret, Management of constipation in Parkin- son's disease, Expert Opin. Pharmacother. 16 (4) (2015 Mar) 547-557.

[9] M. Barichella, C. Pacchetti, C. Bolliri, E. Cassani, L. Iorio, C. Pusani, G. Pinelli,

G. Privitera, I. Cesari, S.A. Faierman, R. Caccialanza, G. Pezzoli, E. Cereda, Probiotics and prebiotic fiber for constipation associated with Parkinson dis- ease: an RCT, Neurology 87 (12) (2016 Sep 20) 1274-1280.

[10] I. Suttrup, T. Warnecke, Dysphagia in Parkinson's disease, Dysphagia 31 (1) (2016 Feb) 24-32.

[11] R.N. Alcalay, Y. Gu, H. Mejia-Santana, L. Cote, K.S. Marder, N. Scarmeas, The association between Mediterranean diet adherence and Parkinson's disease, Mov. Disord. 27 (6) (2012 May) 771-774.

[12] A. Marczewska, R. De Notaris, S. Sieri, M. Barichella, E. Fusconi, G. Pezzoli, Protein intake in Parkinsonian patients using the EPIC food frequency ques- tionnaire, Mov. Disord. 21 (8) (2006 Aug) 1229-1231.

[13] C. Meyers, M.A. Amick, J.H. Friedman, Ice cream preference in Parkinson's disease, Med. Health R. I. 93 (3) (2010 Mar) $91-92$.

[14] B. Lorefa€t, W. Ganowiak, U. Wissing, A.K. Grane'rus, M. Unosson, Food habits and intake of nutrients in elderly patients with Parkinson's disease, Geron- tology 52 (3) (2006) 160-168.

[15] D. Festi, A. Colecchia, S. Pini, E. Scaioli, C. Maffeis, S. Coccheri, M.L. Petroni, Development and application of a simple and powerful tool for nutrition and

lifestyle education for the Italian general population by general practitioners and family paediatricians, Mediterr. J. Nutr. Metab. 2 (2009) 139-144.

[16] V. Bollati, C. Favero, B. Albetti, L. Tarantini, A. Moroni, H.M. Byun, V. Motta,

D.M. Conti, A.S. Tirelli, L. Vigna, P.A. Bertazzi, A.C. Pesatori, Nutrients intake is associated with DNA methylation of candidate inflammatory genes in a population of obese subjects, Nutrients 6 (10) (2014) 4625-4639.

[17] D.C. Frankenfield, E.R. Muth, W.A. Rowe, The Harris-Benedict studies of hu- man basal metabolism: history and limitation, J. Am. Diet. Assoc. 98 (1998) 439-445.

[18] LARN, Livelli Di Assunzione Di Riferimento Di Nutrienti Ed Energia Per La Popolazione Italiana IV Revisione, 2014.

[19] Istituto Nazionale di Ricerca per gli Alimenti e la Nutrizione (I.N.R.A.N.), Tabelle di composizione degli Alimenti.

Aggiornamento 2000, EDRA Med. Publ. New Media (2000).

[20] A. Trichopoulou, T. Costacou, C. Bamia, D. Trichopoulos, Adherence to a Mediterranean diet and survival in a Greek population, N. Engl. J. Med. 348 (2003) 2599-2608.

[21] S. Fahn, R.L. Elton, UPDRS Program Members. Unified Parkinson's disease rating scale, in: S. Fahn, C.D. Marsden, M. Goldstein, D.B. Calne (Eds.), Recent Developments in Parkinson's Disease, vol. 2, Macmillan Healthcare Informa- tion, Florham Park, NJ, 1987, pp. 153-163, 293-304.

[22] M. Hoehn, M. Yahr, Parkinsonism: onset, progression and mortality, Neurology 17 (1967) 427-442.

[23] E. Cereda, R. Cilia, C. Klersy, M. Canesi, A.L. Zecchinelli, C.B. Mariani, S. Tesei,

G. Sacilotto, N. Meucci, M. Zini, I.U. Isaias, E. Cassani, S. Goldwurm, 
M. Barichella, G. Pezzoli, Swallowing disturbances in Parkinson's disease: a multivariate analysis of contributing factors, Park. Relat. Disord. 20 (12) (2014 Dec) 1382-1387.

[24] M.L. Evatt, K.R. Chaudhuri, K.L. Chou, E. Cubo, V. Hinson, K. Kompoliti, C. Yang,

W. Poewe, O. Rascol, C. Sampaio, G.T. Stebbins, C.G. Goetz, Dysautonomia rating scales in Parkinson's disease: sialorrhea, dysphagia, and constipation: Critique and recommendations by movement disorders task force on rating scales for Parkinson's disease, Mov. Disord. 24 (5) (2009 Apr 15) 635-646.

[25] W. Koller, S. Cone, G. Herbster, Caffeine and tremor, Neurology 37 (1) (1987 Jan) 169-172.

[26] M.P. Cecchini, F. Osculati, S. Ottaviani, F. Boschi, A. Fasano, M. Tinazzi, Taste performance in Parkinson's disease, J. Neural Transm. (Vienna) 121 (2) (2014 Feb) 119-122.

[27] F. Sofi, F. Cesari, R. Abbate, G.F. Gensini, A. Casini, Adherence to Mediterranean diet and health status: meta-analysis, BMJ 337 (2008 Sep 11) a1344.

[28] N. Scarmeas, J.A. Luchsinger, R. Mayeux, Y. Stern, Mediterranean diet and Alzheimer disease mortality, Neurology 69 (11) (2007 Sep 11) 1084-1093.

[29] F. Prinelli, M. Yannakoulia, C.A. Anastasiou, F. Adorni, S.G. Di Santo,

M. Musicco, N. Scarmeas, M.L. Correa Leite, Mediterranean diet and other lifestyle factors in relation to 20-year all-cause mortality: a cohort study in an Italian population, Br. J. Nutr. 113 (6) (2015 Mar 28) 1003-1011.

[30] F. Limongi, M. Noale, A. Gesmundo, G. Crepaldi, S. Maggi, Adherence to the Mediterranean diet and all-cause mortality risk in an elderly Italian popula- tion: data from the ILSA study, J. Nutr. Health Aging 21 (5) (2017) 505-513.

[31] National Dysphagia Diet Task Force, National Dysphagia Diet. Standardization for Optimal Care, American Dietetic Association, Chicago, IL, 2002

[32] M. Morishita, S. Mori, S. Yamagami, M. Mizutani, Effect of carbonated bever- ages on pharyngeal swallowing in young individuals and elderly inpatients, Dysphagia 29 (2) (2014 Apr) 213-222.

[33] http://nut.entecra.it/358/31/news/ecco-la-nuova-piramide-alimentaree dellaedieta-mediterranea.html.

[34] J.G. Kalf, B.J. de Swart, B.R. Bloem, M. Munneke, Prevalence of oropharyngeal dysphagia in Parkinson's disease: a meta-analysis, Park. Relat. Disord. 18 (2012) 311-315. 


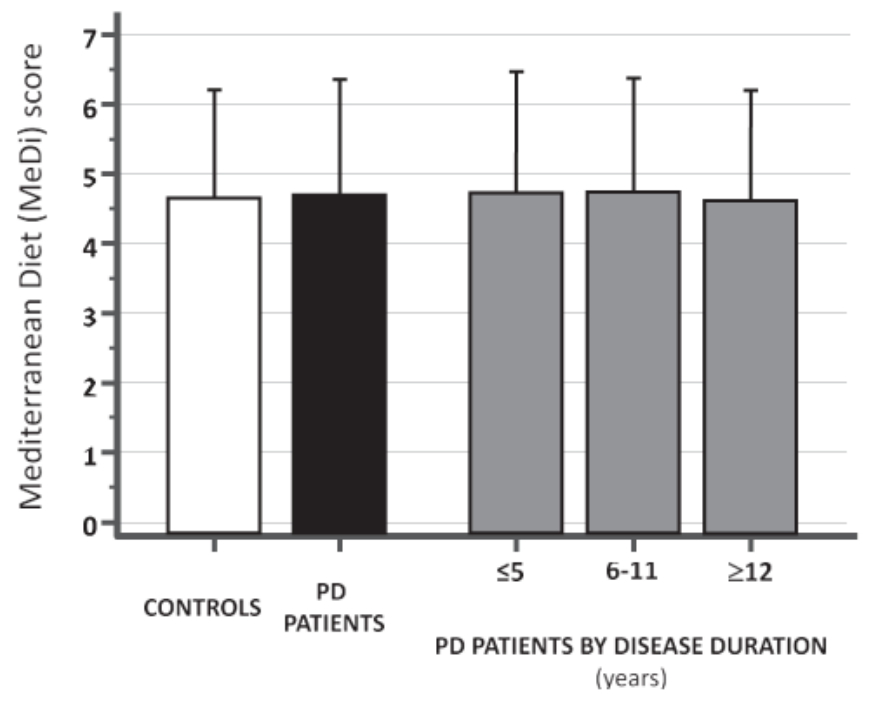

Fig. 1. Mediterranean diet score in the study population (controls, white; PD patients, black) and by disease duration (grey colour). 
Table 1

Principal food groups consumption in the study population.

\begin{tabular}{|c|c|c|c|}
\hline & \multicolumn{3}{|c|}{ Overall population ( $\left.\mathrm{N}^{1 / 4} 1200\right)$} \\
\hline & $\begin{array}{l}\text { Controls } \\
\text { (N } 1 / 4600)\end{array}$ & $\begin{array}{l}\text { PD patientsa } \\
(\mathrm{N} 1 / 4600)\end{array}$ & P-value ${ }^{b}$ \\
\hline Mediterranean diet score & $4.8(1.6)$ & $4.9(1.7)$ & 0.294 \\
\hline \multicolumn{4}{|l|}{ DAIRY PRODUCTS } \\
\hline Skimmed/partly skimmed milk (ml/day) & $118(75)$ & $106(78)$ & 0.007 \\
\hline Whole milk (ml/day) & $101(105)$ & $83(86)$ & 0.001 \\
\hline Soy milk or yogurt (ml/day) & $54(51)$ & $86(73)$ & $<0.001$ \\
\hline Yogurt without sugar (g/day) & $73(90)$ & $52(72)$ & $<0.001$ \\
\hline Sweetened yogurt $(\mathrm{g} /$ day $)$ & $56(71)$ & $68(83)$ & 0.007 \\
\hline Grated cheese (g/day) & $9(7)$ & $13(10)$ & $<0.001$ \\
\hline Fresh cheese (g/day) & $31(23)$ & $32(21)$ & NS \\
\hline Seasoned cheese (g/day) & $16(16)$ & $15(12)$ & NS \\
\hline \multicolumn{4}{|l|}{ BREAD, PASTA AND CEREALS } \\
\hline Refined pasta, rice (g/day) & $66(40)$ & $74(48)$ & 0.002 \\
\hline Whole grain pasta, rice (g/day) & $22(27)$ & $18(24)$ & 0.007 \\
\hline White bread $(\mathrm{g} /$ day $)$ & $76(51)$ & $75(51)$ & NS \\
\hline Whole grain bread $(\mathrm{g} /$ day $)$ & $33(36)$ & $26(36)$ & $<0.001$ \\
\hline Pizza (g/day) & $29(21)$ & $32(23)$ & 0.018 \\
\hline Sandwich/Toast (g/day) & $30(43)$ & $32(41)$ & NS \\
\hline Potatoes $(\mathrm{g} /$ day) & $40(33)$ & $52(40)$ & $<0.001$ \\
\hline Fried potatoes (g/day) & $3(4)$ & $3(4)$ & NS \\
\hline Crackers, breadsticks (g/day) & $13(20)$ & $11(18)$ & NS \\
\hline Biscuits (g/day) & $29(30)$ & $32(28)$ & NS \\
\hline Oatmeal (g/day) & $14(12)$ & $12(17)$ & 0.019 \\
\hline Sweetened breakfast cereals (g/day) & $14(13)$ & $13(18)$ & NS \\
\hline \multicolumn{4}{|l|}{ PROTEIN SOURCES (MEAT, FISH, CURED MEAT, EGGS AND LEGUMES) } \\
\hline Chicken or turkey (g/day) & $34(17)$ & $33(17)$ & NS \\
\hline Veal, beef $(\mathrm{g} /$ day $)$ & $24(21)$ & $23(16)$ & NS \\
\hline Fresh fish (g/day) & $38(27)$ & $34(26)$ & 0.009 \\
\hline Preserved fish (g/day) & $7(7)$ & $6(5)$ & 0.004 \\
\hline Shellfish (g/day) & $13(12)$ & $13(11)$ & NS \\
\hline Cured meat/ham, cooked ham, salami (g/day) & $21(16)$ & $21(15)$ & NS \\
\hline Eggs (g/day) & $10(7)$ & $12(8)$ & $<0.001$ \\
\hline Legumes (g/day) & $43(28)$ & $41(28)$ & NS \\
\hline \multicolumn{4}{|l|}{ FRUIT AND VEGETABLES } \\
\hline Fresh fruit $(\mathrm{g} /$ day $)$ & $233(157)$ & $256(141)$ & 0.008 \\
\hline Citrus fruits (g/day) & $105(102)$ & $94(97)$ & NS \\
\hline Dried fruit in shell $(\mathrm{g} /$ day $)$ & $12(15)$ & $10(12)$ & 0.011 \\
\hline Raw vegetables ( $\mathrm{g} /$ day) & $175(131)$ & $158(100)$ & 0.012 \\
\hline Cooked vegetables (g/day) & $154(104)$ & $179(120)$ & $<0.001$ \\
\hline Cooked tomatoes (g/day) & $45(28)$ & $51(34)$ & 0.001 \\
\hline Vegetable soup/purée (g/day) & $95(82)$ & $112(81)$ & $<0.001$ \\
\hline \multicolumn{4}{|l|}{ SUGAR AND SWEETS } \\
\hline Sugar (g/day) & $8.8(6.4)$ & $8.2(6.8)$ & NS \\
\hline Artificial sweeteners (g/day) & $3.5(2.8)$ & $2.6(2.5)$ & $<0.001$ \\
\hline Milk puddings and custards (g/day) & $12(17)$ & $17(19)$ & $<0.001$ \\
\hline Ice cream (g/day) & $16(23)$ & $21(25)$ & $<0.001$ \\
\hline
\end{tabular}


Chocolate by itself (g/day)

Sweets containing sugar (g/day)

Sweets without sugar (g/day)

Candy bars, snacks ( $\mathrm{g} / \mathrm{d}$ day)

Other snacks (g/day)

DRESSINGS

Olive oil (ml/day)

Seed oil ( $\mathrm{ml} / \mathrm{day})$

Butter (g/day)

Margarine (g/day)

Dressings for pasta

Mayonnaise (g/day)

Ketchup (g/day)

DRINKS

Water (ml/day)

Wine (ml/day)

Beer ( $\mathrm{ml} /$ day)
Other alcoholic drinks (ml/day)

Sweetened fizzy drinks (ml/day)

Sweetened fizzy drinks ( $\mathrm{m} / /$
Light fizzy drinks ( $\mathrm{ml} /$ day)

Light fizzy drinks (ml/day)

Tea (ml/day)

Coffee (ml/day)

$3.5(4.6)$

$4.5(6.4)$

$6(10)$

$13(19)$

28 (15)

$2.0(4.5)$

$1.6(2.4)$

$1.1(1.3)$

$40(35)$

$1.7(1.8)$

1344 (474)

$135(128)$

44 (73)

$7(11)$

$47(92)$
$52(140)$

$52(140)$

$77(105)$

$70(50)$

Abbreviations: NS, not significant.

Data are provided as mean and standard deviation (between parentheses)
$10(15)$

$4.4(5.8)$

$4.0(5.9)$

$4(7)$

$13(17)$

$30(13)$

$3.0(7.5)$

$1.6(3.9)$

$4.0(7.8)$

$38(28)$

$1.8(2.1)$

1092 (443)

$111(116)$

9 (115)

$4(6)$

56 (99)

45 (96)

$95(111)$
$87(141)$

$55(47)$
NS

0.014

NS

$<0.001$

NS

$<0.001$

0.00

.

$<0.001$ 
Table 2

Characteristics of Parkinson's disease patients by the presence of self-reported swallowing disturbances.

\begin{tabular}{|c|c|c|c|}
\hline Variable & $\begin{array}{l}\text { No swallowing disturbances } \\
\text { (N 1/4 528) }\end{array}$ & $\begin{array}{l}\text { Swallowing disturbances } \\
\text { (N 1/4 72) }\end{array}$ & P-value \\
\hline Male gender, $\mathrm{N}(\%)$ & $183(34.7)$ & $40(55.6)$ & 0.001 \\
\hline Age, years [Mean (SD)] & $68.0(9.6)$ & $71.1(7.7)$ & 0.009 \\
\hline Disease duration, years [Mean (SD)] & $9.3(7.0)$ & $8.8(6.1)$ & 0.564 \\
\hline Body weight, kg [Mean (SD)] & $72.1(16.9)$ & $71.5(15.4)$ & 0.775 \\
\hline Body mass index, $\mathrm{kg} / \mathrm{m}^{2}$ [Mean (SD)] & $26.1(5.0)$ & $26.3(5.3)$ & 0.752 \\
\hline \multicolumn{4}{|l|}{ UPDRS score, Mean (SD) } \\
\hline Total, & $39.1(19.9)$ & $67.7(27.7)$ & $<0.001$ \\
\hline Part I, & $2.0(1.9)$ & $3.9(2.3)$ & $<0.001$ \\
\hline Part II, & $12.9(7.1)$ & $23.4(8.7)$ & $<0.001$ \\
\hline Part III, & $21.2(11.7)$ & $37.4(17.6)$ & $<0.001$ \\
\hline Part IV & $3.0(2.7)$ & $3.1(2.7)$ & 0.768 \\
\hline Hoehn-Yahr stage, Mean (SD) & $2.3(0.8)$ & $3.3(1.0)$ & $<0.001$ \\
\hline Calorie intake, kcal/kg/day [Mean (SD)] & $31.3(10.7)$ & $30.8(10.5)$ & 0.709 \\
\hline Protein intake, g/kg/day [Mean (SD)] & $1.2(0.4)$ & $1.2(0.3)$ & 0.896 \\
\hline Carbohydrates intake, g/day [Mean (SD)] & $293.3(81.4)$ & $291.7(107.7)$ & 0.881 \\
\hline Lipids intake, g/day [Mean (SD)] & $84.0(23.3)$ & $81.6(25.8)$ & 0.419 \\
\hline Water intake, $\mathrm{mL} /$ day [Mean (SD)] & $1110(463)$ & $958(465)$ & 0.011 \\
\hline Fluids intake, mL/day [Mean (SD)] & $1611(567)$ & $1467(562)$ & 0.043 \\
\hline Fibers intake, g/day [Mean (SD)] & $32.0(8.5)$ & $32.7(9.5)$ & 0.519 \\
\hline Calcium intake, mg/day [Mean (SD)] & $1019(278)$ & $1058(359)$ & 0.283 \\
\hline Iron intake, mg/day [Mean (SD)] & $13.9(3.4)$ & $13.9(3.4)$ & 0.920 \\
\hline Vitamin D intake, mg/day [Mean (SD)] & $2.6(1.1)$ & $2.7(1.1)$ & 0.470 \\
\hline Vitamin B12 intake, mg/day [Mean (SD)] & $4.6(1.6)$ & $4.3(1.3)$ & 0.128 \\
\hline Vitamin C intake, mg/day [Mean (SD)] & $220(88)$ & $252(95)$ & 0.325 \\
\hline Folate intake, mg/day [Mean (SD)] & $448(127)$ & $472(124)$ & 0.132 \\
\hline
\end{tabular}

Abbreviations: SD, standard deviation; UPDRS, Unified Parkinson's Disease Rating Scale.

${ }^{a}$ According to between-group comparison by Student's t-test or Fisher's exact test as appropriate. 
Table 3

Principal food groups consumption in PD patients by self-reported swallowing disturbances.

\begin{tabular}{|c|c|c|c|}
\hline & $\begin{array}{l}\text { No swallowing disturbances }{ }^{a} \\
(\mathrm{~N} 1 / 4528)\end{array}$ & $\begin{array}{l}\text { Swallowing disturbances } \\
\left(\mathrm{N}^{1 / 4} 72\right)\end{array}$ & P-value \\
\hline Mediterranean diet score & $4.8(1.7)$ & $4.9(1.6)$ & 0.638 \\
\hline \multicolumn{4}{|l|}{ DAIRY PRODUCTS } \\
\hline Skimmed/partly skimmed milk (ml/day) & $109(89)$ & $84(64)$ & 0.022 \\
\hline Whole milk (ml/day) & $85(91)$ & $68(53)$ & NS \\
\hline Soy milk or yogurt (ml/day) & $84(80)$ & $101(73)$ & NS \\
\hline Yogurt without sugar (g/day) & $47(86)$ & $88(65)$ & $<0.001$ \\
\hline Sweetened yogurt (g/day) & $60(63)$ & $127(85)$ & $<0.001$ \\
\hline Grated cheese (g/day) & $12(9)$ & $20(8)$ & NS \\
\hline Fresh cheese (g/day) & $32(21)$ & $32(22)$ & NS \\
\hline Seasoned cheese (g/day) & $15(12)$ & $15(13)$ & NS \\
\hline \multicolumn{4}{|l|}{ BREAD, PASTA AND CEREALS } \\
\hline Refined pasta, rice (g/day) & $74(40)$ & $74(39)$ & NS \\
\hline Whole grain pasta, rice (g/day) & $17(19)$ & $25(18)$ & $<0.001$ \\
\hline White bread (g/day) & $76(54)$ & $68(34)$ & NS \\
\hline Whole grain bread $(\mathrm{g} /$ day $)$ & $29(38)$ & $4(34)$ & $<0.001$ \\
\hline Pizza (g/day) & $33(22)$ & $25(26)$ & 0.005 \\
\hline Sandwich/Toast (g/day) & $31(38)$ & $39(25)$ & NS \\
\hline Potatoes $(\mathrm{g} /$ day $)$ & $50(35)$ & $67(83)$ & 0.002 \\
\hline Fried potatoes (g/day) & $3(4)$ & $3(3)$ & NS \\
\hline Crackers, breadsticks (g/day) & $11(14)$ & $11(5)$ & NS \\
\hline Biscuits (g/day) & $32(27)$ & $32(45)$ & NS \\
\hline Oatmeal (g/day) & $13(20)$ & $5(9)$ & $<0.001$ \\
\hline Sweetened breakfast cereals (g/day) & $12(14)$ & $20(14)$ & $<0.001$ \\
\hline \multicolumn{4}{|c|}{ PROTEIN SOURCES (MEAT, FISH, CURED MEAT, EGGS AND LEGUMES) } \\
\hline Chicken or turkey (g/day) & $32(17)$ & $40(16)$ & $<0.001$ \\
\hline Veal, beef $(\mathrm{g} / \mathrm{day})$ & $24(17)$ & $16(14)$ & $<0.001$ \\
\hline Fresh fish (g/day) & $34(25)$ & $34(26)$ & NS \\
\hline Preserved fish (g/day) & $6(5)$ & $6(5)$ & NS \\
\hline Shellfish (g/day) & $13(11)$ & $13(10)$ & NS \\
\hline Cured meat/ham, cooked ham, salami (g/day) & $21(15)$ & $21(16)$ & NS \\
\hline Eggs (g/day) & $13(8)$ & $5(8)$ & $<0.001$ \\
\hline Legumes (g/day) & $40(27)$ & $48(35)$ & 0.024 \\
\hline \multicolumn{4}{|l|}{ FRUIT AND VEGETABLES } \\
\hline Fresh fruit (g/day) & $260(140)$ & 227 (145) & NS \\
\hline Citrus fruits $(\mathrm{g} / \mathrm{day})$ & $96(103)$ & $79(98)$ & NS \\
\hline Dried fruit in shell $(\mathrm{g} /$ day $)$ & $10(13)$ & $10(12)$ & NS \\
\hline Raw vegetables (g/day) & $167(106)$ & $92(72)$ & $<0.001$ \\
\hline Cooked vegetables (g/day) & $172(112)$ & $230(153)$ & $<0.001$ \\
\hline Cooked tomatoes (g/day) & $51(34)$ & $51(51)$ & \\
\hline Vegetable soup/purée (g/day) & $102(82)$ & $185(81)$ & $<0.001$ \\
\hline \multicolumn{4}{|l|}{ SUGAR AND SWEETS } \\
\hline Sugar (g/day) & $8.3(7.1)$ & $7.5(6.5)$ & NS \\
\hline Artificial sweeteners (g/day) & $2.8(2.6)$ & $1.1(2.6)$ & $<0.001$ \\
\hline Milk puddings and custards (g/day) & $16(18)$ & $24(24)$ & $<0.001$ \\
\hline Ice cream (g/day) & $21(26)$ & $21(21)$ & NS \\
\hline Chocolate by itself (g/day) & $11(16)$ & $2.7(18)$ & $<0.001$ \\
\hline
\end{tabular}




\begin{tabular}{|c|c|c|c|}
\hline Sweets containing sugar (g/day) & $4.7(6.5)$ & $2.2(4.9)$ & 0.002 \\
\hline Sweets without sugar (g/day) & $3.7(5.4)$ & $6.2(3.6)$ & $<0.001$ \\
\hline Candy bars, snacks (g/day) & $4(9)$ & $4(4)$ & NS \\
\hline Other snacks (g/day) & $14(15)$ & $6(23)$ & $<0.001$ \\
\hline \multicolumn{4}{|l|}{ DRESSINGS } \\
\hline Olive oil (ml/day) & $29(13)$ & $37(14)$ & $<0.001$ \\
\hline Seed oil (ml/day) & $2.4(5.9)$ & $7.4(8.5)$ & $<0.001$ \\
\hline Butter (g/day) & $1.7(4.8)$ & $0.2(2.1)$ & 0.009 \\
\hline Margarine (g/day) & $4.3(9.3)$ & $1.8(3.2)$ & 0.024 \\
\hline Dressings for pasta & $41(35)$ & $16(28)$ & $<0.001$ \\
\hline Mayonnaise (g/day) & $1.7(1.9)$ & $2.5(2.5)$ & 0.001 \\
\hline Ketchup $(\mathrm{g} /$ day $)$ & $1.7(2.5)$ & $1.7(1.8)$ & NS \\
\hline \multicolumn{4}{|l|}{ DRINKS } \\
\hline Water (ml/day) & $1110(463)$ & $958(465)$ & 0.011 \\
\hline Wine (ml/day) & $111(116)$ & $111(151)$ & NS \\
\hline Beer (ml/day) & $50(90)$ & $42(113)$ & NS \\
\hline Other alcoholic drinks (ml/day) & $3(4)$ & $11(5)$ & $<0.001$ \\
\hline Sweetened fizzy drinks ( $\mathrm{ml} /$ day) & $51(92)$ & $93(105)$ & $<0.001$ \\
\hline Light fizzy drinks (ml/day) & $42(104)$ & $67(86)$ & $<0.001$ \\
\hline Blended vegetables/fruit, juices ( $\mathrm{ml} /$ day) & $94(114)$ & $95(104)$ & NS \\
\hline Tea (ml/day) & $91(141)$ & $58(144)$ & NS \\
\hline Coffee (ml/day) & $59(47)$ & $26(43)$ & $<0.001$ \\
\hline
\end{tabular}

Abbreviations: NS, not significant.

Data are provided as mean and standard deviation (between parentheses).

b According to between-group comparison by unpaired Student's t-test. 